Aksiologiya: Jurnal Pengabdian Kepada Masyarakat

Vol.4, No.2, Agustus 2020 Hal 141 - 148

ISSN 2528-4967 (print) dan ISSN 2548-219X (online)

\title{
Implementasi Patient Centered Dan Palliative Care Pada Pasien Life Limiting Illness Di Rumah Sakit Pku Gamping Yogyakarta
}

\author{
Elsye Maria Rosa ${ }^{1}$, Erna Rochmawati ${ }^{2}$, Ekorini Sulistyowati ${ }^{3}$ \\ ${ }^{1}$ Magister Manajemen Rumah Sakit, Pascasarjana UMY \\ ${ }^{2}$ Magister Keperawatan, Pasasarjana UMY \\ ${ }^{3}$ Fakultas Kedokteran dan Ilmu Kesehatan UMY \\ Email: elsye@umy.ac.id \\ ${ }^{1}$ Penulis korespondensi
}

\begin{abstract}
ABSTRAK
Life limiting illness (LLI) adalah penyakit yang tidak memiliki harapan untuk dapat disembuhkan, bahkan kematian akan menjadi konsekuensi langsung dari penyakit yang dideritanya. Pendekatan komprehensif yang dapat diberikan pada pasien dengan Life limiting illness (LLI), untuk meningkatkan kualitas pelayanan yaitu dengan menerapkan Patient Centered Care dalam pemberian Perawatan Palliative. Tujuan Pengabdian masyarakat untuk meningkatkan kemampuan petugas kesehatan di RS dalam memberikan pelayanan bagi pasien LLI mengunakan pendekatan Patient Centered Care dan Palliative care. Metode yang digunakan untuk meningkatkan kemampuan petugas adalah dengan menggunakan pelatihan dan role play mengenai peran masing-masing profesi dalam memberikan asuhan kepada pasien LLI. Kemampuan petugas terlihat pada Kepatuhan petugas dalam melakukan pelayanan pada pasien LLI, terlihat pada hasil Kepatuhan pengisian rekam medis secara terpadu oleh semua petugas kesehatan. Hasil dari pengabdian masyarakat dengan menggunakan metode pelatihan dan role play ini secara signifikan mempengaruhi peningkatan kekampuan petugas dalam mengasuh pasien LLI. Hasil yang paling terlihat adalah pengisian rekam medis secara terpadu yang diisi oleh petugas kesehatan.
\end{abstract}

Kata kunci: kepatuhan petugas; palliative care; patient centered care.

\section{The Implementation Patient Centered And Palliative Care In Life Limiting Illness Patients At PKU Gamping Yogyakarta Hospital}

\section{ABSTRACT}

Life limiting illness (LLI) is a disease that has no hope of being cured, even death will be a direct consequence of the illness. A comprehensive approach that can be given to patients with Life Limiting illness (LLI), to improve the quality of service is to apply Patient Centered Care in the provision of Palliative Care. Community service aims to improve the ability of health workers in hospitals to provide services for LLI patients using the Patient Centered Care and Palliative care approaches. The method used to improve officers can use to training and role play regarding the role of each profession in providing care to LLI patients. The ability of officers is seen in the Compliance of officers in providing services to LLI patients, seen in the results of Compliance in filling medical records in an integrated manner by all health workers. The results of community service by using training methods and role play significantly influence the increase in the ability of officers to care for LLI patients. The most visible result is filling medical records in an integrated manner filled by health workers.

Keywords: compliance health service; palliative care; patient centered care. 


\section{PENDAHULUAN}

Di Indonesia jumlah pasien dengan penyakit yang belum dapat di sembuhkan seperti penyakit kanker, penyakit paru obstruksi kronis, cystic fibrosis, stroke, Parkinson, gagal jantung, penyakit genetika dan penyakit infeksi HIV/AIDS baik pada orang dewasa maupun anak mengalami peningkatan yang cukup besar. (Maulida, Oktadini, \& Purnamasari, n.d.). Pasien-pasien dengan penyakit yang mengancam jiwa seperti penyakit kanker dan HIV/AIDS ini menyebabkan pasien dan keluarga sangatlah menderita dan kesulitan dari sisi ekonomi. Karena Mayoritas kasus ini terjadi pada Negara berkembang dimana sedikit aksesibilitas yang cepat dan efektif untuk pengobatan penyakit ini.(Sepúlveda, Marlin, Yoshida, \& Ullrich, 2002). Perawatan paliatif menurut WHO adalah pendekatan untuk meningkatkan hidup yang baik pada pasien dan keluargadalam menghadapi maalah terkait penyakit yang mengancam jiwa melalui pencegahan dan bantuan penderitaan dengan identifikasi awal dan penilaian serta pengobatan tanpa cela rasa sakit, fisik, fsikososial dan spiritual.

Pengembanganperawatan paliatif di Rumah Sakit melalui pendekatan yang efektif dan berbiaya rendah biasanya merupakan satu-satunya alternatif yang layak untuk memenuhi kebutuhan yang utama bagi pasien dan dapat meningkatkan kualitas hidup mereka. Pasien dengan penyakit life limiting illness (LLI) di Indonesia selalu mengalami peningkatan dari tahun ke tahun yaitu pada tahun 2007 sebanyak 9,4\% menjadi 13,3\% pada tahun 2013 (KEMENKES RI, 2013). Di Indonesia angka kejadian penyakit life limiting illness yaitu stroke sebanyak 1.236.825 orang, HIV/AIDS sebanyak 30,935 orang, Tuberkulosis sebanyak 330.910 orang, penyakit asma sebanyak 334 juta orang, penyakit hipertensi sebanyak 84.345 orang, Diabetes Mellitus sebanyak 10 juta orang, penyakit jantung sebanyak 883.447 orang dan penyakit kanker sebanyak 330.000 dengan kejadian tertinggi berada di Yogyakarta (KemenKes, 2014) Kondisi pasien life limiting illness (LLI) sangat membutuhkan perawatan paliatif yang tidak hanya memenuhi kebutuhan fisik, namun juga psikologis, social dan spiritual pasien dan keluarganya (Arianti, 2017) Kebutuhan perawatan paliatif meningkat di dunia maupun di Indonesia. Perawatan paliatif adalah pendekatan untuk meningkatkan kualitas hidup pasien dan keluarga pasien dalam menghadapi penyakit yang mengancam nyawa, dengan cara meringankan penderitaan terhadap rasa sakit dan memberi dukungan fisik, psikososial dan spiritual, yang dimulai sejak diagnosa ditegaknya hingga akhir kehidupan pasien (World Health Organization, 2016). Penyakit dengan perawatan paliatif merupakan penyakit yang sulit atau sudah tidak dapat disembuhkan, perawatan paliatif ini bersifat meningkatkan kualitas pasien.

Pasien life limiting illness (LLI) tidak dapat disembuhkan dan akan di derita seumur hidup, tetapi dapat 
dikendalikan dengan pengelolaan gaya hidup dan melakukan perawatan paliatif untuk meningkatkan kualitas hidup pasien (Lowe \& McbrideHenry, 2012). Kepatuhan dalam melakukan perawatan diri secara rutin yang berlangsung selama hidup akan menjadi tantangan yang besar dan bukan hal yang mudah untuk dilakukan bagi penderita life limiting illness (LLI). Penderita life limiting illness (LLI) biasanya mengalami lebih dari satu tanda gejala yang berbeda dengan tingkat keparahan yang bervariasi, sehingga muncul perasaan bosan dan jenuh dalam melakukan perawatan diri (Amelia, Lelo, Lindarto, \& Mutiara, n.d.). Pemberian pelayanan bagi pasien yang Life limiting illness (LLI) atau penyakit yang tidak memiliki harapan hidup bagi pasien, merupakan tantangan bagi petugas kesehatan, baik Dokter, perawat, Farmasi dan semua petugas di rumah sakit. Kondisi pasien life limiting illness (LLI) sangat membutuhkan perawatan paliatif yang tidak hanya memenuhikebutuhanfisik, namunjuga psikologis, social dan spiritual pasien dan keluarganya. RS PKU Gamping merupakan rumah sakit, berbasis Islami, sehingga menjadi factor Pembeda dengan RS umum lainnya. Mengingat rumah sakit berbasis Islmai, sudah sepatutnya dalam pemberian pelayanan bagi pasien Life limiting illness (LLI) menjadi Pelayanan Unggulan karena berbagis Spiritual dalam mempersiapkan pasien yang menghadapi penyakit terminal. Diperlukan pelayanan yang maksimal untuk memberikan kepuasan pada pasien pada kondisi tersebut.

Salah satu model yang dianjurkan oleh WHO adalah Patient Centered Care merupakan pendekatan yang lebih modern dalam pelayanan kesehatan sekarang. Model ini telah menggeser semua pemberi pelayanan kesehatan menjadi disekitar pasien dan berfokus kepada pasien. Pada model patient centerd care ini diberlakukan kemitraan yang setara (Bergeson \& Dean, 2006). Istilah Patient-Centered Care (PCC) telah meresap menjadi bagian dari layanan kesehatan, namun hingga kini belum ada konsensus yang disepakati secara universal mengenai definisi PCC itu sendiri. Sebagian besar penyedia layanan, pembuat kebijakan, dan peneliti sepakat bahwa PCC mewakili pergeseran paradigma dari tradisional, paternalistis, diarahkan penyedia layanan, dan berfokus pada penyakit menjadi melihat pasien secara holistis (Epstein \& Street, 2011)

\section{METODE}

Metode pelaksanaan pengabdian masyarakat menggunakan pola Actioan Research. Kegiatan dilakukan dengan 2 Siklus, setiap siklus terdiri dari tahap-1 sd tahap -3. Diharapkan dalam 3 bulan perawat di rumah sakit PKU Gamping, dapat memberikan pelayanan dengan Komprehensif dan pasien yang termasuk Life Limiting illness akan diukur tingkat kecemasan dan Kepuasan pasien dapat meningkat. Tempat pelaksanaan pengabdian masyarakat, di ruang perawatan Medical dan Non Medical Surgical Bangsal Ar-royyan (Kelas-3). 
Kapasitas 31 tempat tidur. Jumlah Perawat terdiri atas 19 Perawat pelaksana, 1 Kepala Ruangan dan 2 orang PPJA (Perawat Penanggung Jawab Asuhan).

Model pelaksanaan Pengabdian Masyarakat dalam Pendayagunaan Patient Centered Care dan Palliatif

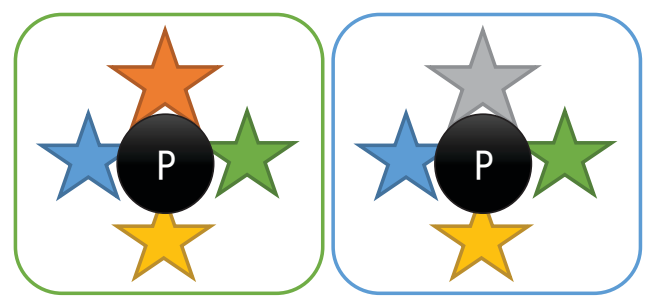

Care, adalah sebagai berikut:

Tahap-1 ; Briefing Team Palliaf ; tujuannya untuk memperoleh Kesamaan Persepsi pada team PCC Palliatif Care pada pasien life limiting illness (LLI). Untuk memperoleh kesamaan persepsi tim mengenai PCC dan paliative care maka akan terlebih dahulu dilakukan pelatihan untuk tenaga kesehatan di Rumah Sakit PKU Muhammadiyah Gamping. Pelatihan ini akan meliputi:

1. komunikasi dalam palliative care, 2. penatalaksanaan nyeri dan gejala lain (fisik, psikologis dan spiritual), 3 . pelaksanaan family meeting dan end-of-life care. Pelatihan ini akan dilakukan menjadi 3 tahap pelaksanaan.

Tahap-2: Visiting Team : tujuannya memberikan informasi dan edukasi kepada Pasien dan keluarga mengenai program asuhan yang akan diberikan team PCC pada pasien life limiting illness (LLI)

Tahap-3: Responding Team dan Pasien: tahap mengevaluasi pencapaian asuhan yang diberikan team PCC baik dari pasien maupun dari pemberi pelayanan.

Ketiga tahapan tersebut akan selesai dalam 3 bulan, karena tahapan tersebut dilakukan secara simultan. Adapun Model Penerapan Patient Centered Care, memiliki Variasi Penempatan Petugas sebagai berikut:

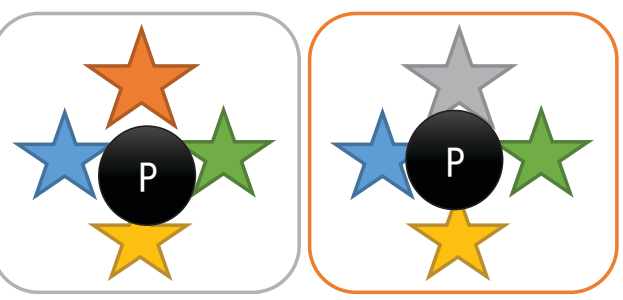

Gambar 1: Distribusi Team Patient Centered Care

Keterangan gambar:

$$
\begin{aligned}
& \text { th }=\text { Dokter }
\end{aligned}
$$

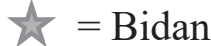

$$
\begin{aligned}
& \text { 支 = Perawat } \\
& \text { 文 = Gizi } \\
& \text { 낫 Apoteker }
\end{aligned}
$$

Model penerapan PCC dibagi menjadi dua proses, yaitu briefing dan visiting oleh Tim PCC. Tim PCC meliputi berbagai profesi klinis antara lain: 2 dokter spesialis mata yang bergantian ditemani oleh 2 perawat, dan 1 ahli farmasi.

\section{HASIL DAN PEMBAHASAN}

Tahap -1:Kegiatan awal dilakukan Pelatihan mengenai pelaksanaan Patient Cantered Care. Diharapkan semua petugas kesehatan memahami pentingnya pelaksanaan Patient Centered Care pada pasien.Pelatihan dilakukan pada semua petugas kesehatan yang terdiri dari semua Profesi: Dokter, 
Perawat, Farmasi, Gizi dan Petugas Fisioterapi. Pelatihan dilakukan selama 2 hari dengan pola pemberian konsep mengenai Palliative Care dan Patient Cantered Care. Pelatihan di akhiri dengan melakukan role play pelaksanaan patient centered care, pemberian kasus oleh narasumber. Hasil respon petugas setelah dilakukan role play: perawat merasa pesimis Patient Centered Care dapat dilaksanakan karena mengatur dokter Penanggung Jawab (DPJP) yang merupakan Dokter spesialis sangat sulit.

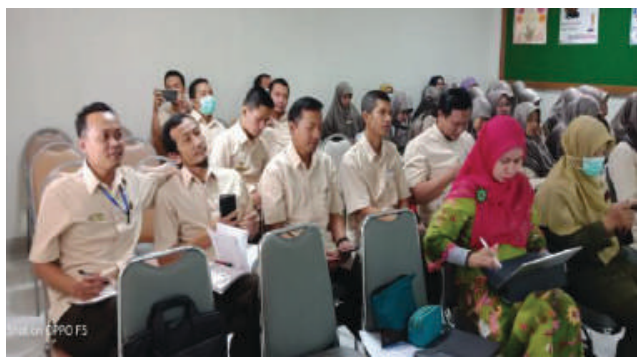

Gambar 2: Peserta Pelatihan di RS PKU Gamping

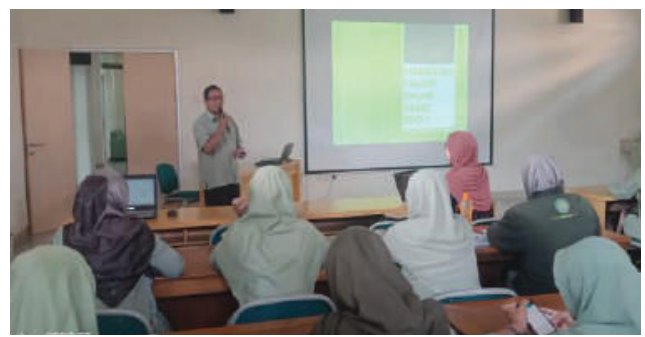

Gambar 3 : Pelatihan Topik: Pasien

Terminal dalam Pelayanan Palliative Care oleh pak Arif Riyanto

Gambar 2 sd 6 menunjukkan proses pelaksanaan proses pelaksanaan Pengabdian Masyarakat pada petugas Kesehatan yang berada di RS.PKU Gamping Yogyakarta. Pelatihan dan role play di laksanakan untuk meningkatkan kemampuan Kognitif, Psikomotor dan Attitude dari Petugas

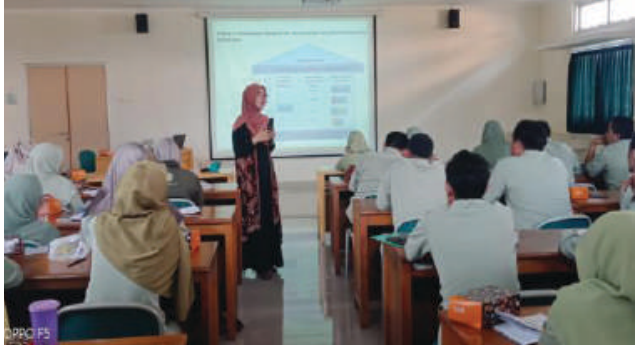

Gambar 4: Pelatihan dengan Topik: Patient Centered Care oleh Elsye Maria Rosa

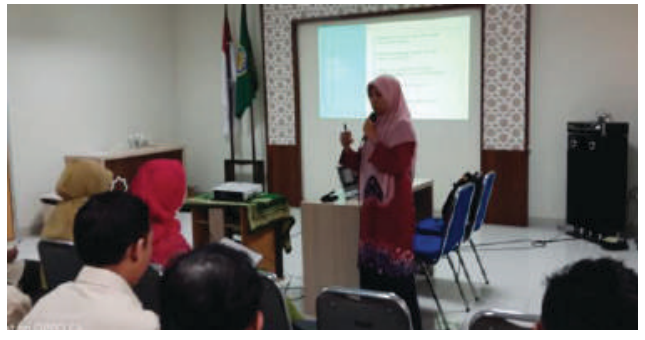

Gambar 5: Pelatihan dengan Topik: Palliative Care oleh Erna Rachmawati

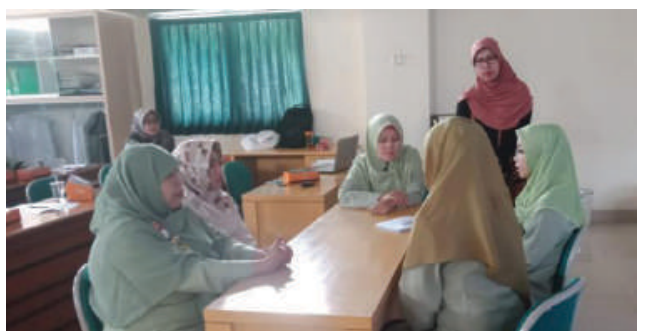

Gambar 6: Role Play Pelaksanaan Briefing Patient Centered Care

dalam memberikan asuhan pada pasien.

\section{Tahap -2: Visiting Team}

Hasil Kepatuhan pelaksanaan Patient Cantered Care di Rumah Sakit

Pada gambar 7 di bawah ini, memperlihatkan Kepatuhan dari petugas Kesehatan dalam pengisian Rekam medis secara Terpadu. Dimana Ketidakpatuhan petugas dalam pengisian rekammedis secara terpadu ternyata sangat sulit untuk direalisasikan. Terlihat dari 4 rekam medis yang dilakukan 
audit menunjukkan masih tingginya pengingatanterus-menerus, paradigma Ketidakpatuhan terutama pada pelaksanaan Assesment. PCC akan terlaksana dengan baik di rumah sakit.

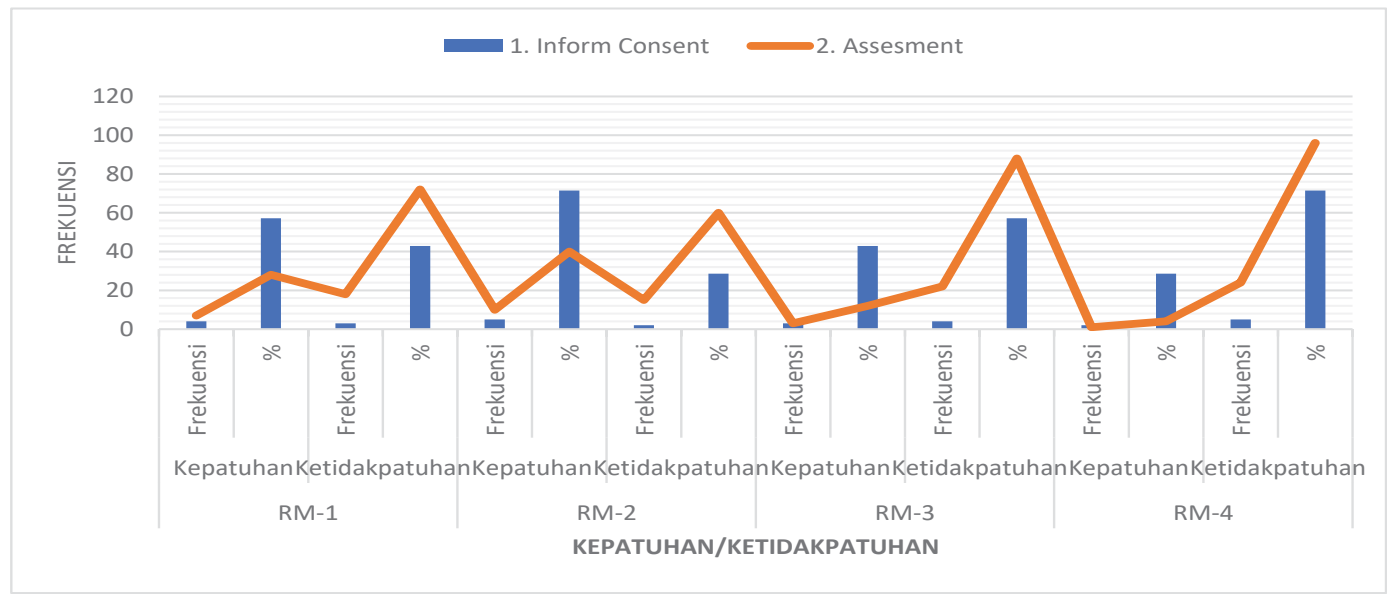

Gambar 7: Kepatuhan Petugas dalam menjalankan Sebelum Pelatihan Patient Centered Care

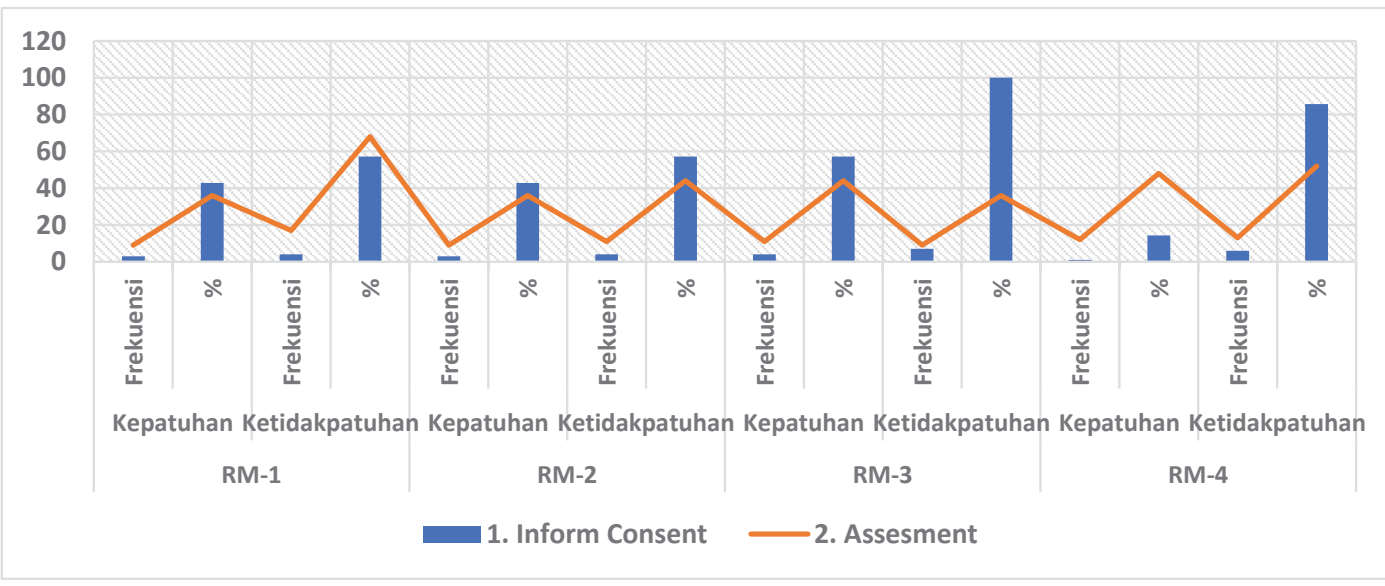

Gambar 8:Kepatuhan Petugas Kesehatan Menjalankan Patient Centered Care Sesudah Pelatihan

Sedangkan pada Gambar-8, Semua rekam medis pasien yang menderita Life Limitting Illnes menunjukkan bahwa Kepatuhan petugas sudah ada peningkatakan, dapat dilihat dari Penjelasan Inform Consent serta Pelaksanaan Assesment yang dilakukan oleh semua petugas kesehatan. Walaupun tidak dapat dipungkiri masih ada Ketidakpatuhan dari petugas kesehatan dalam menjalankan Patient Centered Care. Tetapi dengan berjalannya waktu dan
Tahap-3:Respon dari Team Patient

\section{Centered Care}

Petugas kesehatan saat menjalankan visitasi tim PCC tidak dapat hadir secara komplit /full team sehingga sehingga untuk mendapatkan kesepakatan mengenai tindakan yang akan diberikan menggunakan media rekam medis yang terpadu. Hanya belum semua petugas, membaca hasil assessment dari petugas lainnya. Tindakan yang diberikan dari masingmasing petugas dilaksanakan sendiri- 
sendiri.

\section{SIMPULAN}

Pendekatan Patient centered care pada perawatan Palliative bagi pasien dengan Life Limiting Illness menjadi suatu pendekatan utama untuk meningkatkan kualitas pelayanan bagi pasien. Petugas kesehatan pada semua profesi yang dapat memberikan asuhan sesuai dengan kewenangannya masing-masing sehingga pola kolaborasi antar profesi dapat terjalin dengan baik. Interaksi yang baik diantara profesi dalam pemberian asuhan dapat meningkatkan kepuasan kerja dan profesionalisme petugas serta meningkatkan outcome dari pasien.

\section{Ucapan Terima Kasih}

Kegiatan Pengabdian Masyarakat ini dibiayai oleh LP3M Universitas Muhammadiyah Yogyakarta, sesuai dengan SK No: 2816/SK-LP3M/ I/2019 tentang Penerima Hibah Pengabdian Masyarakat Batch -1Program Peningkatan Tri Dharma Perguruan Tinggi Universitas Muhammadiyah Yogyakarta, tahun akademik 2018/2019.

\section{DAFTAR PUSTAKA}

Amelia, R., Lelo, A., Lindarto, D., \& Mutiara,E.(n.d.). ANALYSISOF FACTORS AFFECTING THE SELF-CARE BEHAVIORS OF DIABETES MELLITUS TYPE 2 PATIENTS IN BINJAI, NORTH SUMATERA-INDONESIA. 8.

Arianti, A. (2017). IDENTIFIKASI GEJALA PADA PASIEN DENGAN LIFE LIMITING ILLNESS. Retrieved from http://repository.umy.ac.id/ handle/123456789/13533

Bergeson, S. C., \& Dean, J. D. (2006). A Systems Approach to PatientCentered Care. Jama, 296(23), 2848-2848. https://doi. org/10.1001/jama.296.23.2848

Bezold, C. (2005). The future of patient-centered care: Scenarios, visions, and audacious goals. Journal of Alternative and Complementary Medicine (New York, N.Y.), 11 Suppl 1, S7784. https://doi.org/10.1089/ acm.2005.11.s-77

Delaney, L. J. (2018). Patient-centred care as an approach to improving health care in Australia. Collegian, 25(1), 119-123. https://doi.org/10.1016/j. colegn.2017.02.005

Epstein, R. M., \& Street, R. L. (2011). The Values and Value of PatientCentered Care. Annals of Family Medicine,9(2), 100-103.https:// doi.org/10.1370/afm.1239

KemenKes, R. I. (2014). Profil Kesehatan RI 2013. Jakarta.

KEMENKES RI. (2013). Riset Kesehatan Dasar (RISKESDAS) 2013. https://doi.org/10.1007/ s13398-014-0173-7.2

Lowe, P., \& Mcbride-Henry, K. (2012). What factors impact upon the quality of life of elderly women with chronic illnesses: Three women's perspectives. Contemporary Nurse, 41(1), 18-27. https://doi.org/10.5172/ conu.2012.41.1.18

Maulida, M. N., Oktadini, N. R., \& Purnamasari, N. (n.d.). GAMBARAN PENGETAHUAN DAN SIKAP PERAWAT MENGENAI PERAWATAN PALIATIF. 5.

Meterko, M., Wright, S., Lin, H., Lowy, E., \& Cleary, P. D. (2010). Mortality among Patients with Acute Myocardial Infarction: The Influences of Patient-Centered Care and 
Evidence-Based Medicine.

Health Services Research. https://doi.org/10.1111/j.14756773.2010.01138.x

Sepúlveda, C., Marlin, A., Yoshida, T., \& Ullrich, A. (2002). Palliative Care: The World Health Organization's Global Perspective. Palliative Care, 24(2), 6.

World Health Organization. (2016). World health statistics. 2016, 2016,. Retrieved from http:// search.ebscohost.com/login.as px? direct $=$ true $\&$ scope $=$ site $\& \mathrm{db}$ $=$ nlebk $\& \mathrm{db}=$ nlabk $\& A N=14824$ 49 